\title{
Geophysical Prospecting for Geothermal Resources in the South of the Duero Basin (Spain)
}

\author{
Ignacio Martín Nieto*(D), Pedro Carrasco García, Cristina Sáez Blázquez ${ }^{\mathbb{D} \text {, }}$ \\ Arturo Farfán Martín $\mathbb{D}^{D}$, Diego González-Aguilera $\mathbb{D}$ and Javier Carrasco García
}

Department of Cartographic and Land Engineering, University of Salamanca, Higher Polytechnic School of Avila, Hornos Caleros 50, 05003 Avila, Spain; Retep81@usal.es (P.C.G.); u107596@usal.es (C.S.B.);

afarfan@usal.es (A.F.M.); daguilera@usal.es (D.G.-A.); j.carrasco@usal.es (J.C.G.)

* Correspondence: nachomartin@usal.es; Tel.: +34-920-353-500 (ext. 3820)

Received: 28 August 2020; Accepted: 7 October 2020; Published: 15 October 2020

check for updates

\begin{abstract}
The geothermal resources in Spain have been a source of deep research in recent years and are, in general, well-defined. However, there are some areas where the records from the National Institute for Geology and Mining show thermal activity from different sources despite no geothermal resources being registered there. This is the case of the area in the south of the Duero basin where this research was carried out. Seizing the opportunity of a deep borehole being drilled in the location, some geophysical resources were used to gather information about the geothermal properties of the area. The employed geophysical methods were time-domain electromagnetics (TDEM) and borehole logging; the first provided information about the depth of the bedrock and the general geological structure, whereas the second one gave more detail on the geological composition of the different layers and a temperature record across the whole sounding. The results allowed us to establish the geothermal gradient of the area and to discern the depth of the bedrock. Using the first $200 \mathrm{~m}$ of the borehole logging, the thermal conductivity of the ground for shallow geothermal systems was estimated.
\end{abstract}

Keywords: geothermal resources; geophysical prospecting; time-domain electromagnetics; borehole logging; geothermal gradient; thermal conductivity

\section{Introduction}

The use of geophysical methods for the characterization of geothermal resources has been applied in many countries of the world. A large number of works have been carried out for this purpose using a wide variety of techniques. Among the many research works conducted in Poland [1] was a very interesting use of a new approach that used common-reflection-surface (CRS) seismic 3D methods to characterize deep geothermal reservoirs [2]. Additionally, the United States has been subject of numerous works that have characterized geothermal resources by geophysical methods [3]. We can also name Italy, Iceland, China and many others as examples of application of these techniques [4-6].

Increasing knowledge about the geothermal resource in a given place is essential to promote its use. For this reason, geophysical prospecting campaigns, which play an important role in characterizing these resources, are an important step prior putting them into operation.

Geothermal resources in Spain had not been exploited in a significant way until recently. Some ground source heat pump geothermal systems have been implemented in recent years, but other geothermal possibilities with fluid temperatures above low enthalpy ones are widely unknown and therefore unexploited $[7,8]$.

Different works have been published on the distribution of geothermal resources in Spain $[9,10]$. However, this has not significantly contributed to boosting to the implementation of this type of energy 
system, which may be very important in the future for the lowering of emissions from heating/cooling systems in order to meet the objectives set by the European Union [11].

Figure 1 shows the usual depth/temperature distribution of different geothermal resources. Region I embraces resources that need to make use of a heat pump in heating/cooling geothermal systems, those that can be used directly for heating purposes and for thermal industrial processes that take place at those temperatures are in region II, and there are geothermal resources capable of producing electricity in region III. In Spain, most of the installed geothermal systems have come from region I [12], with only some region III resources being under evaluation in the Canary Islands [13].

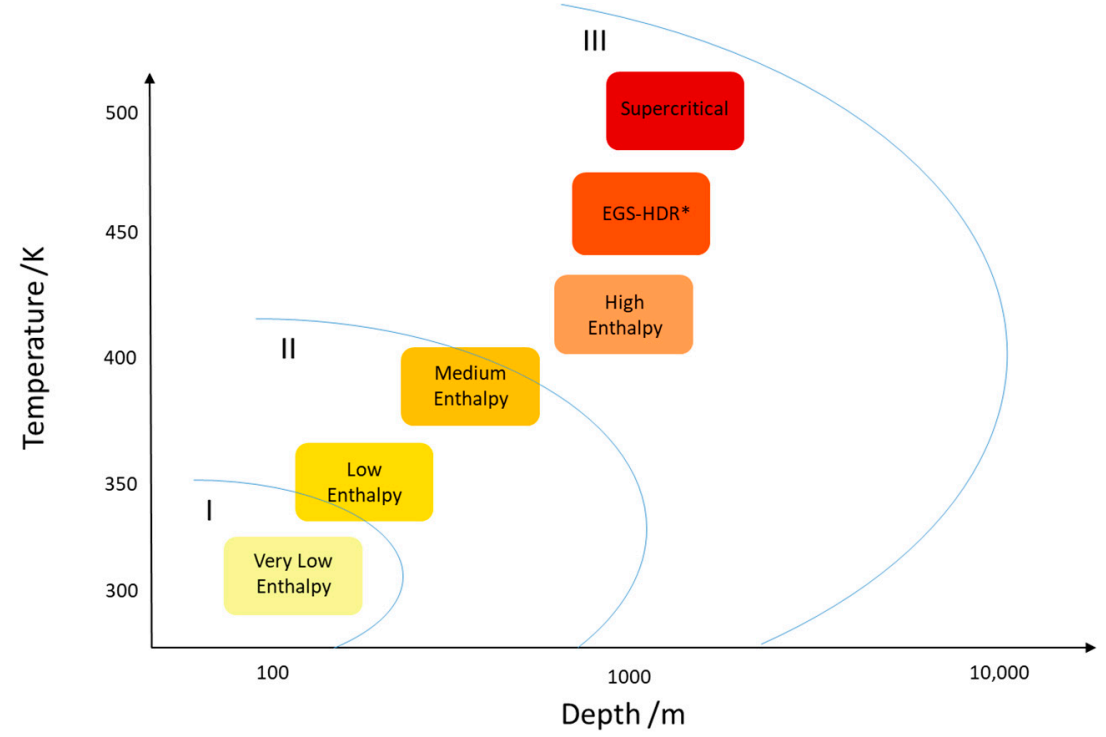

Figure 1. Types of geothermal resources (* EGS stands for enhanced geothermal systems and HDR stands for hot dry rock).

Works on the distribution of geothermal resources in the Iberian Peninsula often mention very little about the zone in which this research is located (sedimentary layers in the south-center of the Duero river basin) [14-16], although there have been several hints about the possible existence of some kind of geothermal resources [17] more likely to belong to region II from Figure 1.

Taking advantage of a water well drilling operation in the area of interest at about $700 \mathrm{~m}$ deep, geophysical studies were carried out to determine the detailed geological structure, as well as borehole logging of the sounding, to characterize the composition and the geothermal gradient of the area. We intended to determine the depth of the bedrock, as well as the depth and temperature of the different aquifers crossed by the borehole. All this was done with the intention of identifying the area's geothermal resources and their possibilities of use.

The geophysical work carried out included:

- The time domain electromagnetic (TDEM) method was used to estimate the geological structure of the sedimentary layers even beneath the length of the borehole in study. This method also revealed the depth of the bedrock in the area and how far it was from the end of the borehole logging performed. The geological information obtained with this method could be used to estimate the thermal properties of the ground to assess the performance of future geothermal systems in the location.

- Borehole logging, crossing the entire length of the sounding with a downhole probe, was able to collect data from multiple sensors that provided varied detailed information about the geological composition, traversed aquifers, temperatures throughout the borehole, etc. Additionally, from the detailed information about the geological formations crossed by the logging, it was possible to 
estimate the thermal properties of the ground to design well fields in geothermal systems with more detail than with the TDEM method.

The results were not completely satisfactory. The thermal gradient from the borehole logging was not as promising as expected. However, in the final part of the borehole, a more pronounced increment of temperature seemed to appear. Perhaps drilling closer to the bedrock (now clearly located by the TDEM method) could find a thermal gradient capable of providing low and medium enthalpy resources that could be used for processes in the food industry, which is a force for economic development in the area.

\section{Materials and Methods}

\subsection{Time Domain Electromagnetic Prospecting Methods}

The time domain electromagnetic (TDEM) method of geophysical prospecting was a very important innovation in the field of applied geophysics at the beginning of the 1980s [18,19]. From those years on, the application of the method has allowed for remarkable experiences regarding the capacity of this technique in hydrological science, mining, underground environmental pollution quantification, archeology, etc. In addition, in these years, its advantages over electrical vertical sounding (EVS), limitations, and fields of application have been set. The accumulated experience and the technological improvement in devices have transformed this method into one of the most effective in current geophysics.

Within the TDEM method is time domain electromagnetic sounding (TDEMS), which we performed for this work. TDEMS is a geophysical tool capable of providing very detailed information on the distribution of subsurface resistivity; it can determine its variations both laterally and vertically.

The TDEMS system is classified within the electromagnetic research systems with artificial sources.

Performing a TDEMS consists of injecting a constant current in a loop or transmitter coil (Tx) to generate a constant primary magnetic field. When the current flowing through the Tx is instantaneously interrupted, the primary magnetic field ceases to be constant and decreases its value over time until it becomes zero. In agreement with Faraday's law, when the ground is exposed to a variable magnetic field in time and a series of electromagnetic inductions of electric currents (Eddy currents) occur in the subsoil (Figure 2). These currents flow in paths closed by the subsoil, laterally migrating in depth and decreasing the current's intensity over time. This, in turn, generates a decreasing transient secondary magnetic field on the surface.

This secondary field induces a time-varying voltage in the receiving loop ( $R x)$. The voltage drop contains information on the resistivity of the ground because the magnitude and distribution of induced currents depend on the resistivity of the medium.

The electromotive force created in the Rx can be described as follows (Equation (1)) [20]:

$$
E=K * A * N
$$

where $E$ is the electromotive force $(\mathrm{V}), K$ is a constant that depends on the magnetic field generated in the $\operatorname{Tx}\left(\mathrm{V} / \mathrm{m}^{2}\right), A$ is the area of the $\mathrm{Rx}\left(\mathrm{m}^{2}\right)$, and $N$ is the number of turns in the Tx.

The generated Eddy currents are inducted in the ground and tend to turn away from the generation point at an approximate angle of $30^{\circ}$. The depth of penetration at a given time is given by the following expression (Equation (2)) [20]:

$$
Z_{d}=(2 t / \sigma \mu)^{1 / 2}
$$

where $Z_{d}$ is the depth of penetration (m), $t$ is the time (s), $\mu$ is the permeability $(\mathrm{H} / \mathrm{m})$, and $\sigma$ is the electrical conductivity $(\mathrm{S} / \mathrm{m})$.

From Equation (2), it follows that the electrical conductivity of the medium conditions the penetration of the geophysical method. The penetration is directly proportional to the medium resistivity, so the less resistive the medium (marls, clays, etc.), the less the system penetration. 


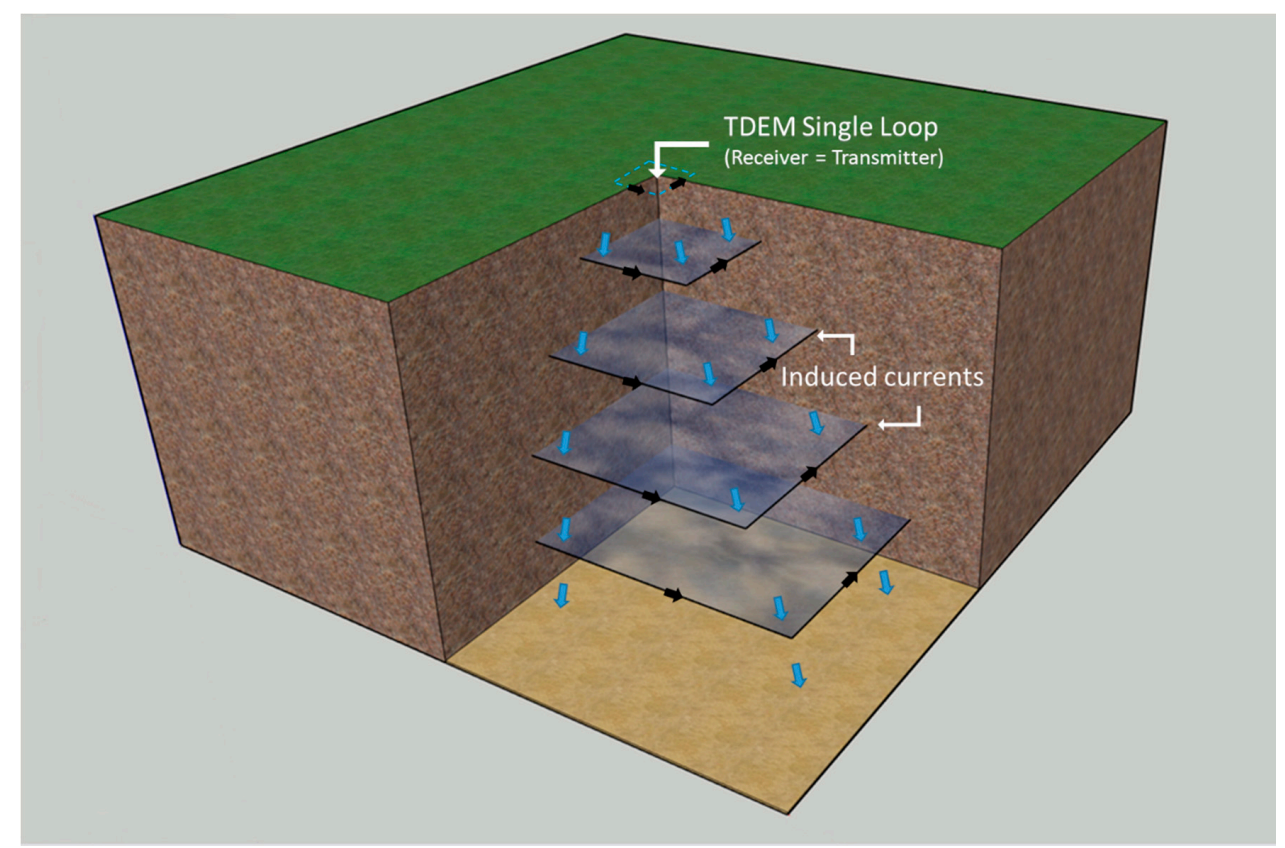

Figure 2. Eddy currents to the underground.

The maximum depth to which we can measure is obtained through Equation (3) [20]:

$$
Z_{\max }=\left(2 / 25 \pi^{3}\right)^{1 / 10}\left(M / \sigma V_{\text {noise }}\right)^{1 / 5}
$$

where $|M|$ is the magnetic moment (module) $\left(\mathrm{Am}^{2}\right)$ and $V_{\text {noise }}$ is the ambient noise $(\mathrm{V})$.

Thus, the maximum depth does depends not only on the moment or conductivity but also on the level of ambient noise [21].

Therefore, the useful depth of research depends on:

- $\quad$ The dimensions of the Tx.

- The intensity of the current flowing through the Tx.

- The duration of the transitory observation time.

- The electrical resistivity of the surface layers and of the ground in general.

The processing of TDEMS (1D) field data is like that of other electrical prospecting methods [22]. Electromotive force, measured as a function of time, becomes the apparent resistivity that is fed an inversion software, which calculates the ground structure with the best possible fit to the curve of the obtained apparent resistivity.

Recently, a system was developed that allows for a 1D dataset to be processed in the form of profiles, thus obtaining an electromagnetic tomography. The software performs joint processing based on specific algorithms (the Spiker algorithm, which adjust the observed apparent resistivities in the best possible way [23]) to obtain 2D sections of the apparent conductivity of the ground. This treatment allows one to correlate the results of the quantitative interpretation of the various TDEMSs (1D) grouped in the same profile, thus obtaining a geo-electric section. The lateral variations of resistivity (lateral resolution) depend on the distance between the loops. More details on the data treatment can be found in Section 3.

\subsection{Borehole Logging}

The principal aim of geophysical borehole logging techniques is to build a vertical map of the geological composition, some properties of the crossed materials, and the groundwater hydrological conditions of the area. 
The determination of which parameter(s) to measure mainly depends on the characteristics of the borehole and the desired information.

Log interpretation mainly includes singular hydro-geophysical units and the sediment layers identified in the descriptive report. Data are collected and stored digitally, and they can be presented at any requested scale.

Table 1 gives a brief description of the magnitudes that were measured in our borehole logging test, as well as their appliances.

Table 1. Borehole logging devices, parameters, and purposes.

\begin{tabular}{ccc}
\hline Log & Parameter Measured & Purpose \\
\hline Natural gamma & Natural gamma radioactivity & $\begin{array}{c}\text { Lithology and the estimation of clay } \\
\text { content }\left({ }^{40} \mathrm{~K}\right)\end{array}$ \\
Fluid temperature & Temperature of borehole fluid & Geothermal gradient and water flow \\
Fluid resistivity & Resistivity of borehole fluid & Water flow and quality \\
Spontaneous potential (SP) & $\begin{array}{c}\text { Electrical potentials between probe } \\
\text { and surface electrodes }\end{array}$ & $\begin{array}{c}\text { Lithology, water quality, and, in some } \\
\text { cases, fractures in crystalline rock }\end{array}$ \\
Single point resistance (SPR) & Resistance of materials between & Lithology, fracture identification, and \\
probe and ground surface electrode & location of well screens \\
Normal resistivity & Apparent resistivity of material & Lithology and water quality \\
\hline
\end{tabular}

\subsection{Devices}

The TDEMSs were performed by the deployment of 3 square $400 \times 400 \mathrm{~m}$ loops. The used measuring technique was the one of coincident loops. The repetition of measurements was carried out for each loop to obtain a greater precision in the collection of the field data; this meant that for each one of the three TDEMSs, one register was made by using a staking of 1000 repetitions of the measurement per channel; 73 channels were measured for each one of the registers. However, due to the size of the used loop $(400 \times 400 \mathrm{~m})$, from channels 35 to 40 , the results were heavily affected by the background noise. This was also the case for the first channels, so the first and last channels were discarded in the subsequent processing of the field data.

The equipment used for the TDEMS was the TerraTEM, from the Australian company MONEX GeoScope Geophysical Manufacturing And Consulting Ltd. The TerraTEM incorporates a $10 \mathrm{amp}$ transmitter and a true simultaneous $500 \mathrm{kHz} 3$-component receiver. Spectral analysis, combined with DSP options, allows the user to monitor and identify local sources of noise; these may be removed using additional filters specific to local site conditions. This device is equipped with a diagnosis menu that provides access to a spectrum analyzer as well as time-domain views of the input signal for the rapid troubleshooting or optimization of acquisition parameters to ambient site conditions.

For the borehole logging, a downhole probe, logging winch, and data logger from Mount Sopris Instruments Company were used. In Table 2, the technical specifications of the sensors included in the downhole probe are detailed.

Table 2. Downhole probe sensor's specifications [24].

\begin{tabular}{cc}
\hline Sensor & Specifications ${ }^{1}$ \\
\hline Natural gamma & Natural gamma sensor composed of a sodium iodide crystal. Gamma \\
& range: $0-100,000$ cps. Accuracy: $1 \%$. Resolution: $0.02 \%$. \\
Fluid temperature & Temperature sensor: linear and fast response semi-conductor. Range: \\
Spontaneous potential (SP) & $-20-80^{\circ} \mathrm{C}$. Accuracy: $1 \%$. Resolution: $0.4{ }^{\circ} \mathrm{C}$. \\
Single point resistance (SPR) & Range: $-1500-1500 \mathrm{mV}(\mathrm{DC})$. Accuracy: $1 \%$. Resolution: $0.04 \%$. \\
Resistivity (fluid and normal) & Range: $0-10,000 \Omega$. Accuracy: $1 \%$. Resolution: $0.02 \%$. \\
& Sensors: stainless steel electrodes. Range: $0-10,000 \Omega \cdot \mathrm{m}$. Accuracy: $1 \%$. \\
\hline
\end{tabular}

${ }^{1}$ Data from manufacturer (Mount Sopris Instruments, Denver, CO, USA). 
Figure $3 \mathrm{~A}, \mathrm{~B}$ shows the TDEM device during the data acquisition in the location under study and the scheme of the devices for the borehole logging works, respectively.
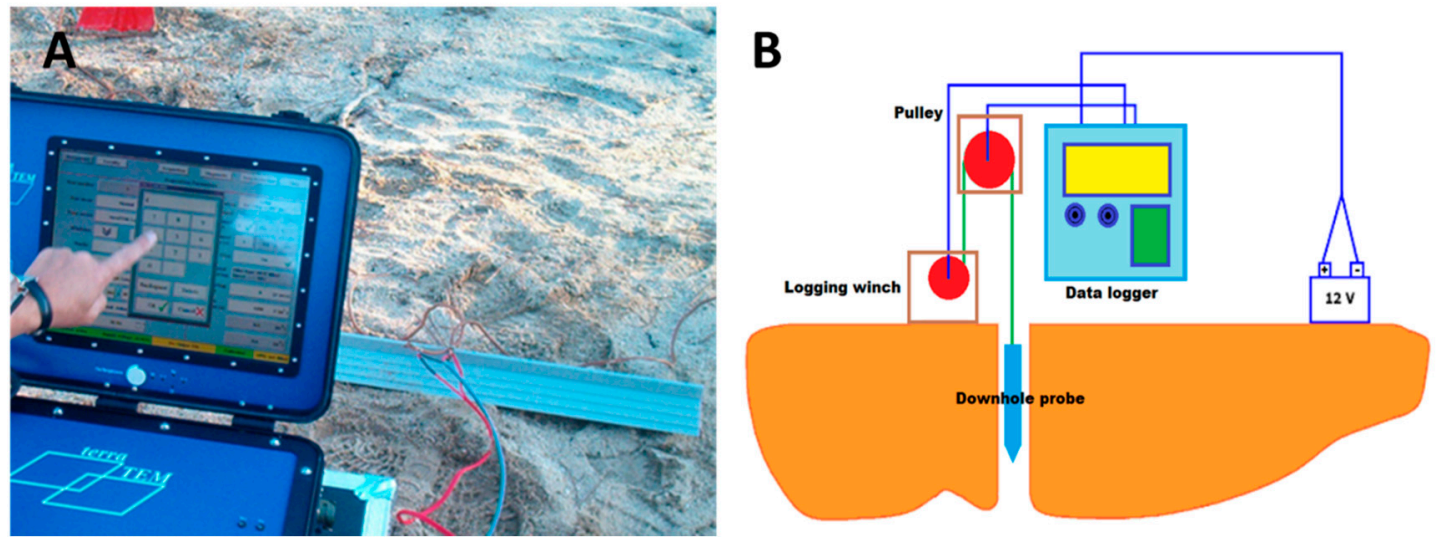

Figure 3. (A) TerraTEM time domain electromagnetic (TDEM) device during the data acquisition phase of this study. (B) Borehole logging equipment (scheme).

\subsection{Site Description}

The area selected for this study is in the north of the province of Ávila (Spain) in the south part of the Duero basin. The southern half of this basin, although not especially renown for this reason, is an area where there are numerous upwellings of groundwater with higher temperatures than could be expected [17]. Figure 4 shows the location and in-situ scheme of the performed TDEM loops.

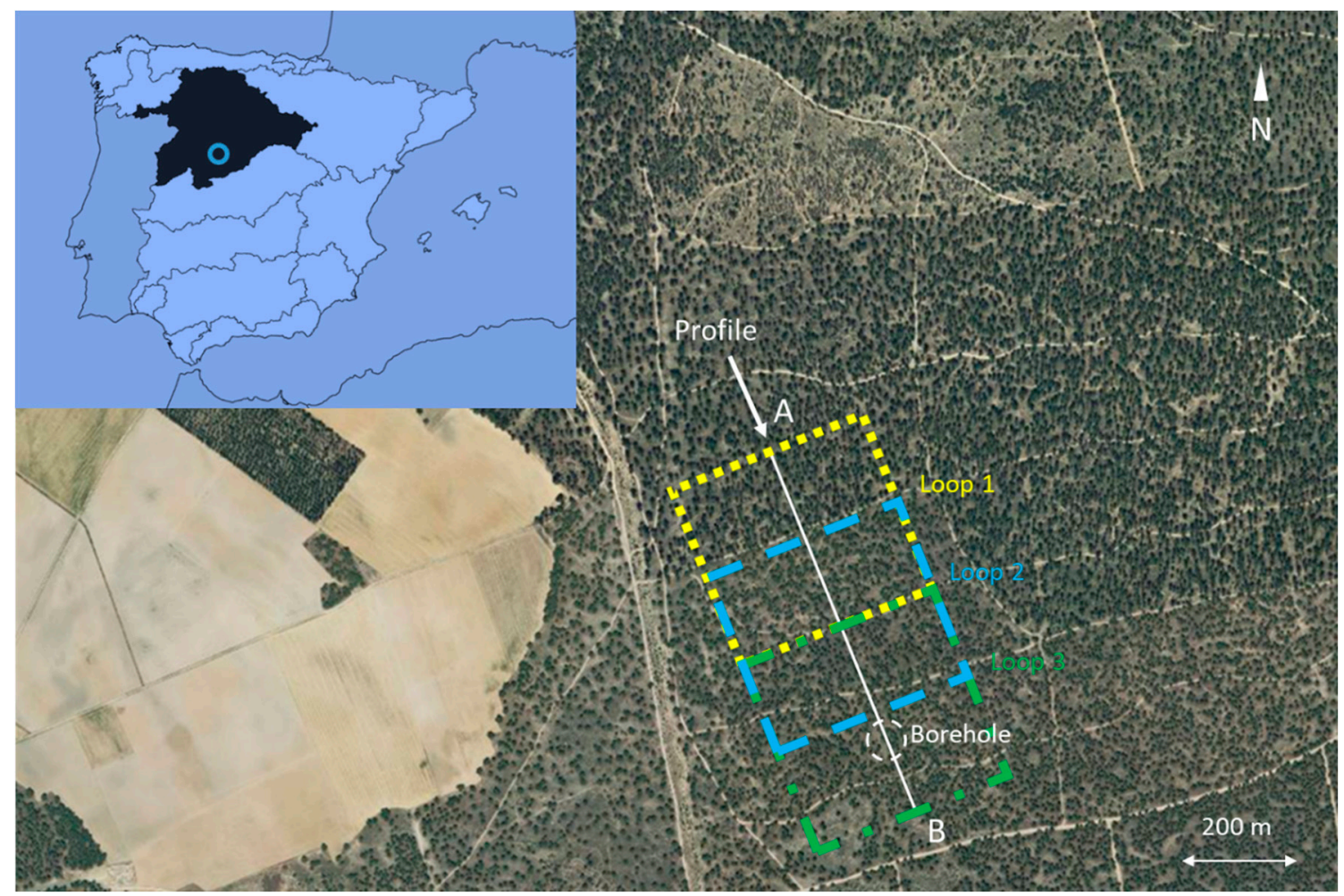

Figure 4. Location and site of prospecting data.

In Table 3, the coordinates of the location of the 2D profile from the TDEM method are presented. 
Table 3. Location of the 2D profile endpoints (Figure 3).

\begin{tabular}{ccc}
\hline & \multicolumn{2}{c}{ Profile Location } \\
\hline & Latitude & Longitude \\
\hline A & $40^{\circ} 55^{\prime} 27.5^{\prime \prime} \mathrm{N}$ & $4^{\circ} 42^{\prime} 40.3^{\prime \prime} \mathrm{W}$ \\
B & $40^{\circ} 55^{\prime} 6.7^{\prime \prime} \mathrm{N}$ & $4^{\circ} 42^{\prime} 31.2^{\prime \prime} \mathrm{W}$ \\
\hline
\end{tabular}

As stated in the introduction, this particular location was chosen because the Geological and Mining Institute of Spain [25], where thermal water sources are described for each region, has recorded several promising aquifer formations due to the presence of hot springs in the area.

\subsubsection{Geological Description of the Area}

The area is characterized by the horizontal or sub horizontal arrangement of materials. Figure 5 shows the geological environment of the location.

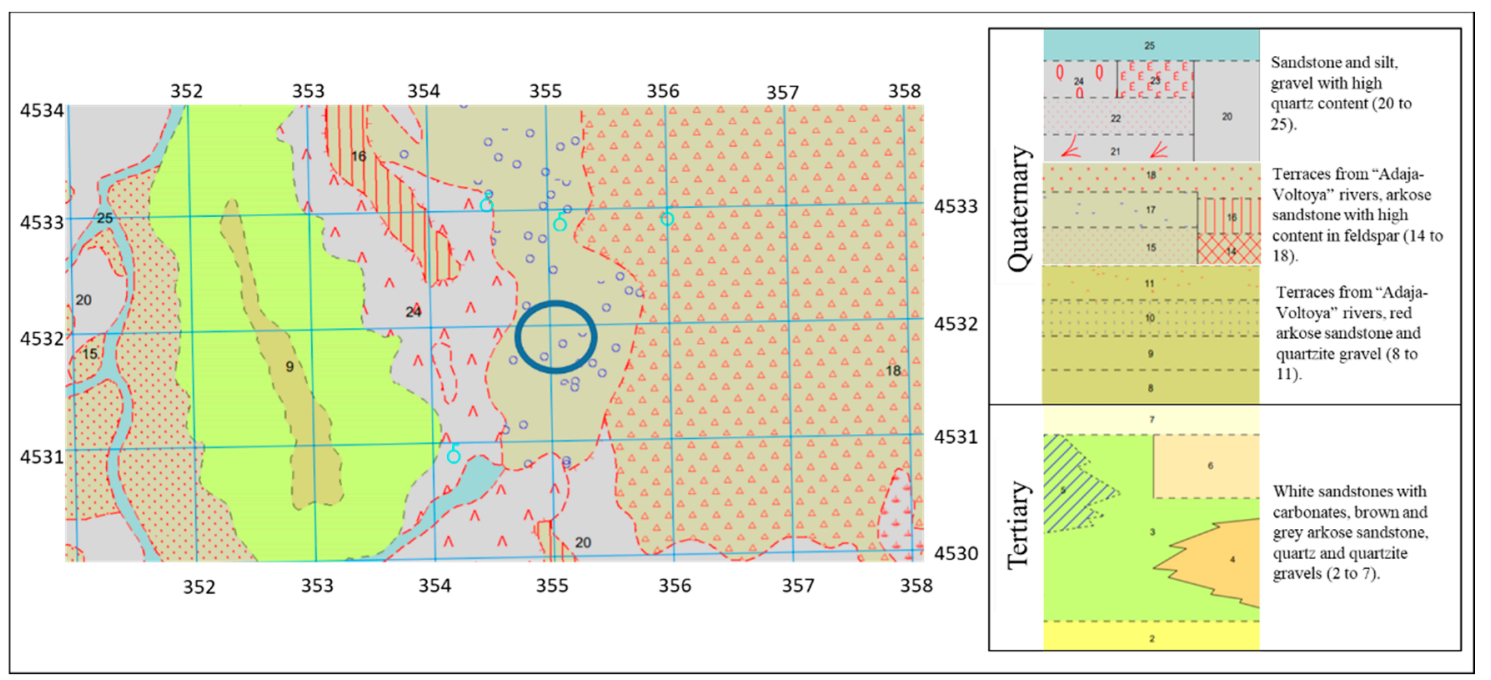

Figure 5. Geological survey of the study area [26].

Quaternary-age materials are the most common in the location, with some tertiary-age ones appearing mainly on the left side. Concerning the quaternary materials, in general, all the terraces are made up of sand and gravel, with the most recent with predominance being quartz gravels and the old ones mainly being quartzite with a high percentage of quartz in their composition. As for the average grain size, it decreased from the oldest to the most modern levels with sizes of 7-12 and $3-4 \mathrm{~cm}$, respectively.

Tertiary-age materials, which are the oldest of the outcropping rocks in the area, are mainly a set of arkosic sedimentary rocks of beige and whitish color. There are also some cemented sandstones from the lower-middle Miocene [27].

At the specific point where the project was carried out, marked with a blue circle in Figure 4, there are surfaces with or without a deposit of fluvial arkoses with quartz gravel and feldspar, along with the possibility of the appearance of large blocks near the surface.

\subsubsection{Hydrogeological Survey}

Concerning the hydrogeological indications that were evaluated to choose the location of the study area, information about existing thermal water in the neighborhood was one of the most decisive sources of information. The Geological and Mining Institute of Spain, specifically its Geological Resources Research Department, has been working in the field of mineral and thermal water for decades. The fundamental objective of this service is to contribute to the knowledge and protection 
of mineral water through research. This labor includes advising administrations, disseminating knowledge about mineral and thermal water to society in general, and promoting and developing the economic sector that uses this water. As such, there is a complete geospatial database that gathers all the information encoded through the years, as well as a large number of documents kept in the archive that are currently digitized and systematized. There is also the Mineral Water Information System (SIAM) for the optimal management of all this information that constitutes a powerful multifunctional tool.

In Figure 6, the hydrogeological map of the area under study is shown; locations A, B, C, D, E, and $\mathrm{F}$ are locations with some evidence of thermal water. The Geological and Mining Institute of Spain [28] records the hot springs and classifies them into areas with proven or historical evidence of thermal water and officially declared water.

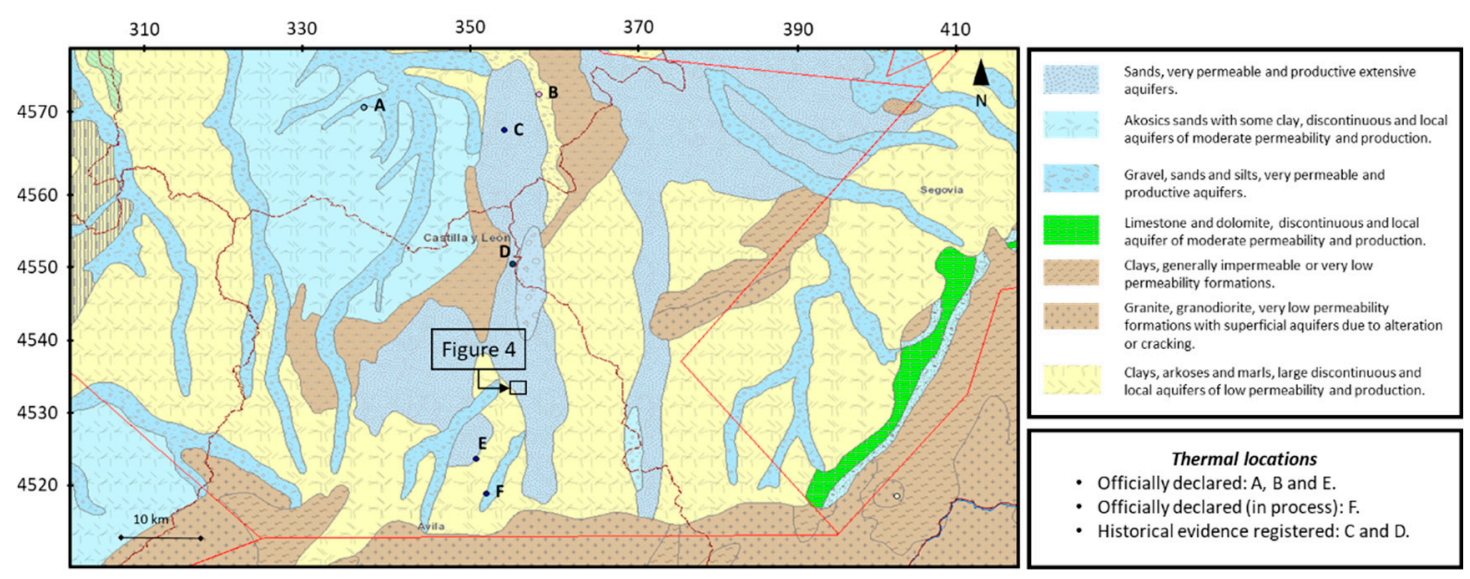

Figure 6. Hydrogeological map of the area [28].

Figure 6 shows the main sandy aquifer units in the surroundings of our location, which are represented in blue. As can be seen, there are numerous pieces thermal water evidence in the same aquifer of this study, as well as in close ones. Table 4 shows a description of each one of these pieces of thermal evidence. In Appendix A, the chemical composition of the thermal water is included (when available).

Table 4. Thermal locations from Figure 5 [25].

\begin{tabular}{ccc}
\hline Location & Description & Current Status \\
\hline A & $20 \mathrm{~m}$ deep spring water drilling. Lithology sands, clays, \\
and silts. Water temperature: $14.1^{\circ} \mathrm{C}$. & Officially declared thermal water. Spa in operation. \\
B & 234 m deep spring water drilling. Lithology clays, silts, & Officially declared thermal water. Spa in operation. \\
C & sands, and gravel. Water temperature: $21.5^{\circ} \mathrm{C}$. & Historical evidence. \\
D & Historical evidence. & Dry in surface. Inactive. \\
E & $85 \mathrm{~m}$ deep spring water drilling. Lithology, clays, and & Officially declared thermal water. \\
F & silts. Water temperature: $16.5^{\circ} \mathrm{C}$. & Officially declared thermal water (in process). \\
\hline
\end{tabular}

After gathering all this information on the location of study, the geophysical prospecting work detailed in the previous subsection was carried out.

\section{Results}

The 2D profile of the ground were obtained with the TDEM method. Figure 7 shows the results. The location of the bore hole where the logging was carried out is also presented. 


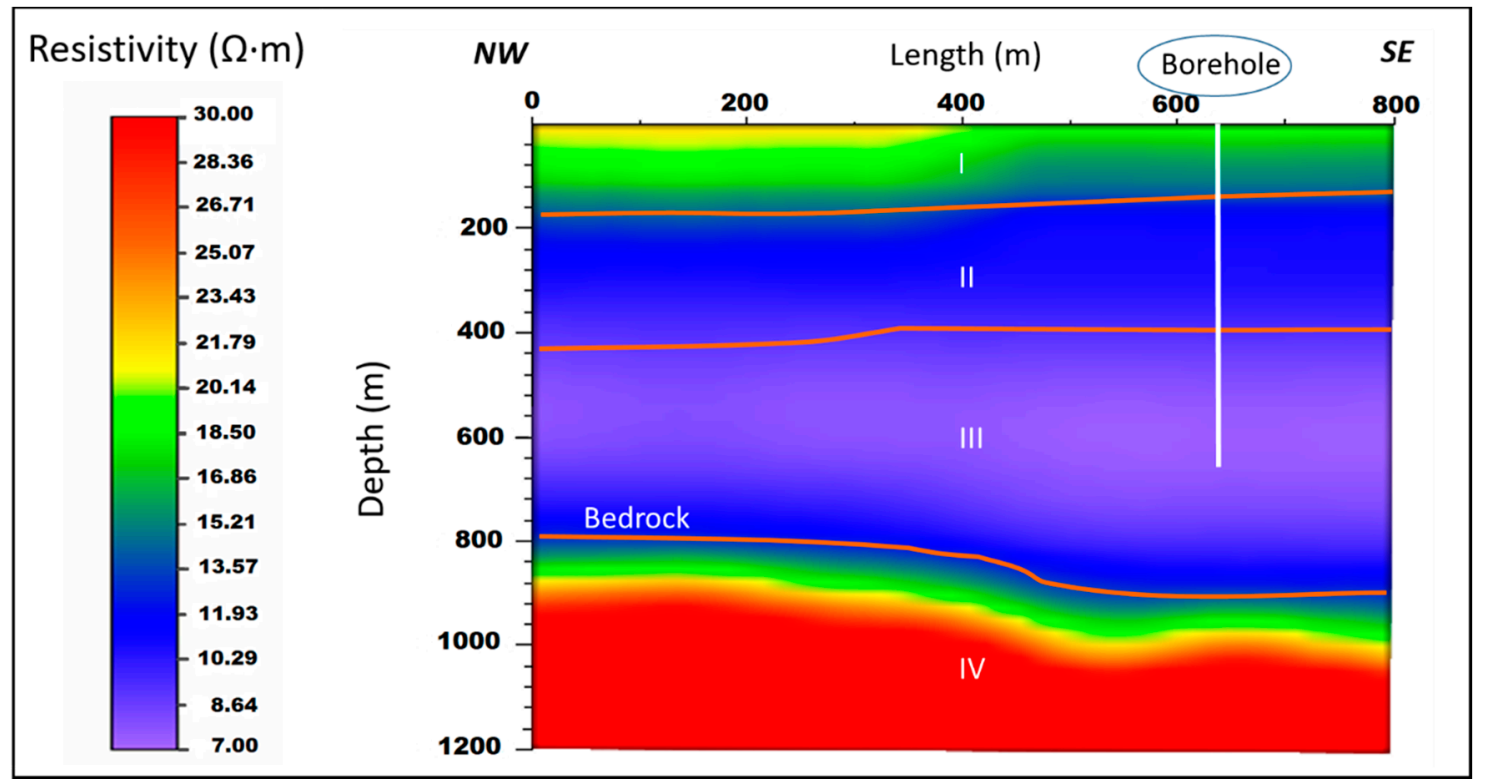

Figure 7. 2D profile gathered from the TDEM method.

A, B, C, and D in Figure 6 represent the different layers. A brief explanation of the composition of each one can be seen in Table 5 .

Table 5. Layers from Figure 6.

\begin{tabular}{ccc}
\hline Layer & Description & Thickness \\
\hline I & Neogene. Sands and clays. & $120-170 \mathrm{~m}$. \\
II & Neogene. Altered clays with levels of sands and silts. & $\approx 260 \mathrm{~m}$. \\
III & Neogene. Clays and marl with levels of sands and silts. & $350-500 \mathrm{~m}$. \\
IV & Early Tertiary. Sandstone, shales, and schists. & Bedrock at $800 \mathrm{~m}$ (NW) to $900 \mathrm{~m}$ (SE). \\
\hline
\end{tabular}

The borehole logging was carried out, and the results of the last $155 \mathrm{~m}$ (from 530 to $685 \mathrm{~m}$ of depth) are shown in this chapter. The rest of the logging data for the whole well can be found in Appendix B (Figures A1-A7).

Table 6 shows the key to the different columns in the borehole logging report. Colored text corresponds to the color of the lines on the report.

Table 6. Key to the borehole log report.

\begin{tabular}{cc}
\hline Column & Measurements \\
\hline A & Depth $(\mathrm{m})$ \\
\hline B & $\begin{array}{c}\text { Natural Gamma }(0-150 \text { counts per second) } \\
\text { Spontaneous Potential }(300-431 \mathrm{mV}) \\
\text { Single point resistance }(35-55 \Omega)\end{array}$ \\
\hline C & Normal resistivity $(0-30 \Omega \cdot \mathrm{m} ; \mathrm{R} 8, \mathrm{R} 16, \mathrm{R} 32$, and R64.) \\
\hline D & Lithology (graphical description) \\
\hline E & Lithology (description) \\
\hline F & $\begin{array}{r}\text { Fluid resistivity }(214-208 \Omega \cdot \mathrm{m}) \\
\text { Temperature }\left(10-30{ }^{\circ} \mathrm{C}\right)\end{array}$ \\
\hline
\end{tabular}


Figure 8 shows the depth from -530 to -608 of the borehole logging report. Sand layers located at -536 and $-550 \mathrm{~m}$, colored in yellow in column D, were reported as most promising for water use of the borehole. These levels should be considered during the casing process of the well.

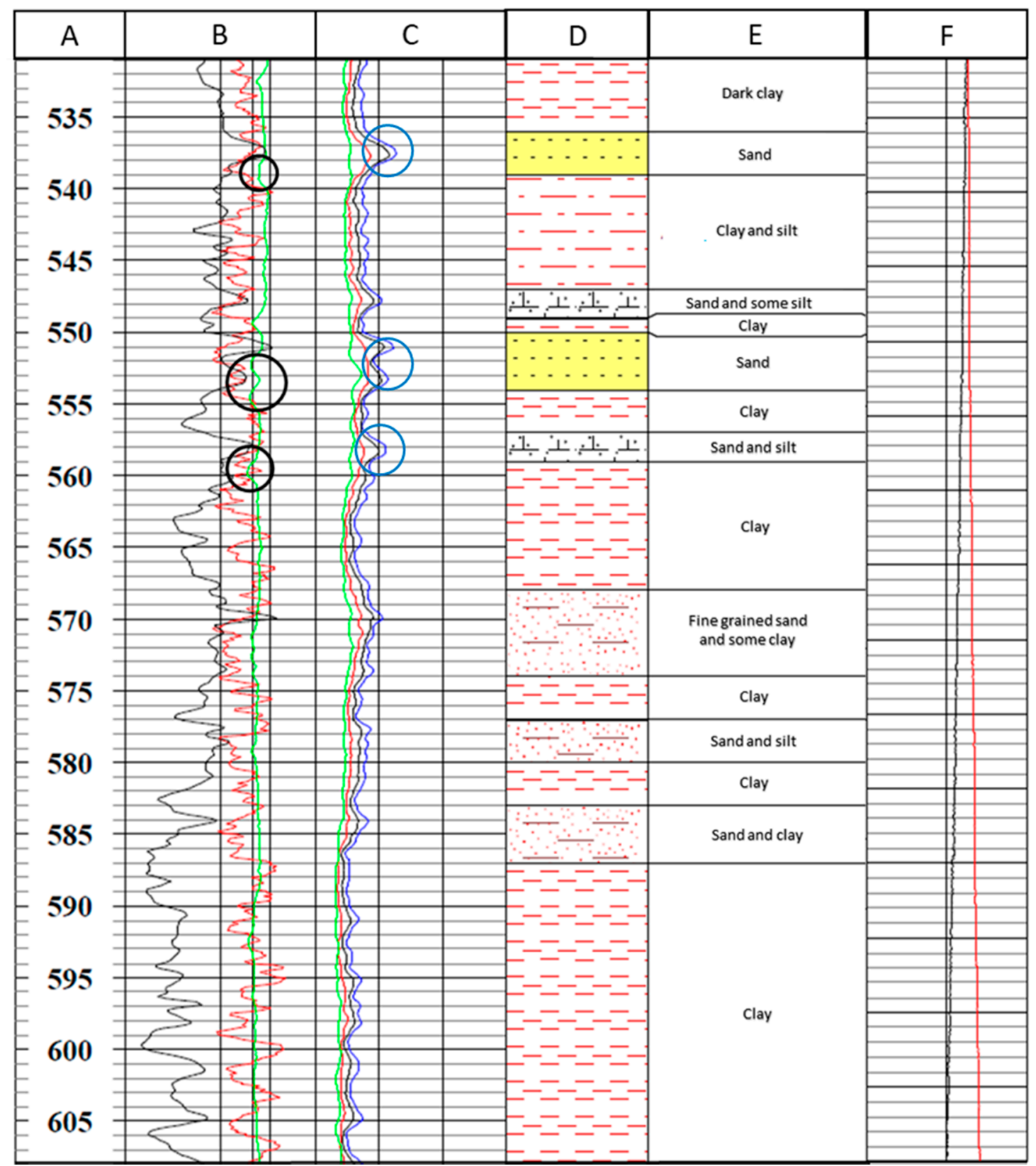

Figure 8. Borehole logging report (from -531 to $-608 \mathrm{~m}$ ).

The black and blue circles in Figure 8 show water inclusions into the borehole from the crossed layers. The black circles point the behavior of the SP (spontaneous potential; $\mathrm{mV}$ ) reacting to water income with a left leap due to the lower salt content in this water than in the drilling mud. The blue circles indicate the descent in resistivity due to the sand layers with water content. Notice that there is a small depth gap between the sensor's response in SP and the resistivity, which may have been due to the different locations of the sensors in the downhole probe (which was approximately $2.15 \mathrm{~m} \mathrm{long}$ ).

Figure 9 shows the depth from -609 to -686 of the borehole logging report. It was the end of the logging, so the borehole may have had about $10 \mathrm{~m}$ more length. However, for safety reasons, the device stopped data logging at this depth. 


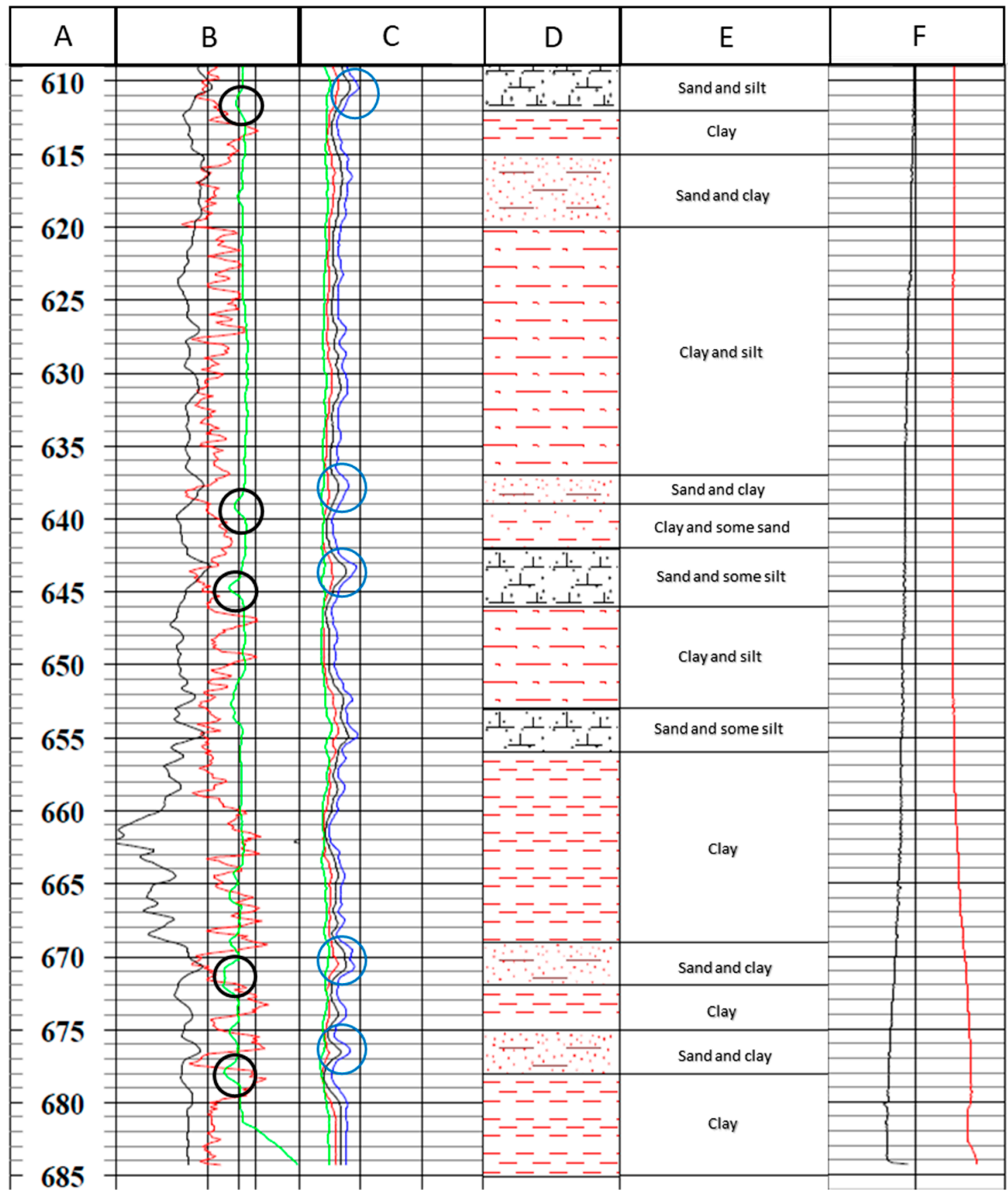

Figure 9. Borehole logging report (from -609 to $-685 \mathrm{~m}$ ). End of the borehole logging.

The black circles in the SP and the blue circles in the resistivity column mean the same as in Figure 8 . Here, there were no sand-only layers, as in the previous section; however, as shown by the logging, there were some layers with sand and water contents entering the borehole. The sudden increase in temperature and fluid resistivity observed at $-683 \mathrm{~m}$ in Figure 9 should be discarded and can be attributed to pulley braking.

\section{Discussion}

As shown in Section 3, the temperature results of the borehole logging where not as promising as expected given the thermal evidence in the area. Figure 10 shows a comparison between the expected thermal gradient of the location declared by the IDAE (Diversification and Energy Saving Institute of Spain) [29] and the one measured by the temperature sensor in the downhole probe. 


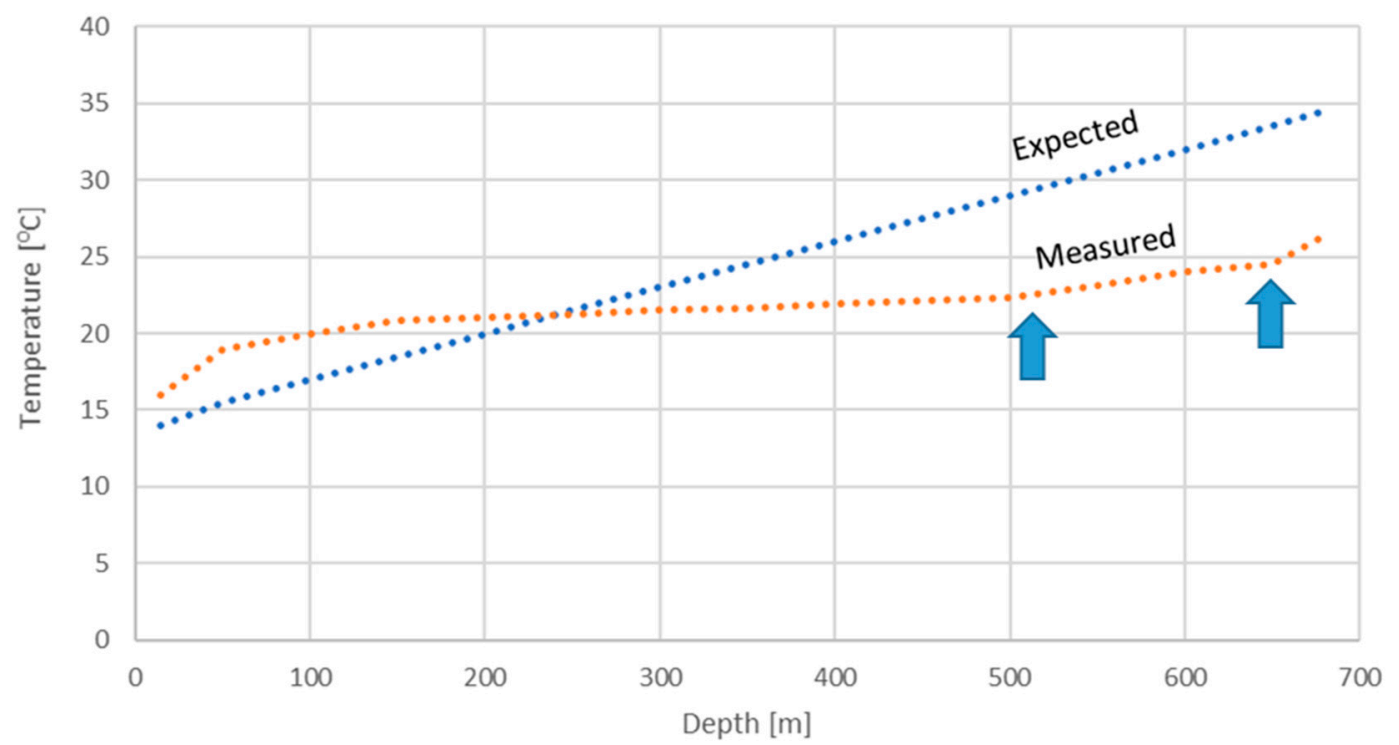

Figure 10. Expected vs. measured temperatures across the borehole.

In the measured thermal gradient from the previous figure, two turning points marked with the blue arrows can be observed at around -550 and $-650 \mathrm{~m}$ of depth. These two sudden increases in temperature seemed to be in line with the contributions of water to the sounding of the layers marked with circles in Figures 8 and 9 found at these depths. Additionally, the approach to the bedrock can explain the fast temperature rising rate as depth increased.

This increase in temperature, if it was caused by the proximity of the bedrock, would indicate that looking for drilling sites closer to its surface would give better results for the thermal gradient. As shown from the TDEM prospecting profile results in Figure 7, the bedrock can be found at $-800 \mathrm{~m}$ of depth in the north-west side of the area; in comparison, the bedrock can be found at $-1000 \mathrm{~m}$ of depth in the borehole. Maybe the thermal gradient would be higher there.

\section{Thermal Properties of the Ground by Geophysical Methods}

According to previous work, some thermal properties of the ground can be determined by geophysical prospecting methods [22,30,31].

In the previous work "Comparative Analysis of Different Methodologies Used to Estimate the Ground Thermal Conductivity in Low Enthalpy Geothermal Systems" [31], the authors estimated the thermal conductivity of the ground with some geophysical methods (including electrical ones and borehole logging) and then compared the results with the thermal response test (TRT) performed in the same area (the TRT is considered to be the main assay used to obtain the thermal conductivity of the ground [32]).

Following the methods described in the previously mentioned work, the thermal conductivity of the ground was estimated with the data from the TDEM method and the borehole logging. Due to the usual depth of the wells in low-enthalpy geothermal systems of around a maximum of $200 \mathrm{~m}$, this depth was taken into consideration here. In Table 7, the obtained results are shown.

Table 7. Estimated thermal conductivities from the geophysical methods according to [26].

\begin{tabular}{ccc}
\hline Geophysical Method & Thermal Conductivity $(\mathbf{W} / \mathbf{m} \cdot \mathbf{K})$ & Usual Deviation from TRT \\
\hline TDEM (NW) & 1.48 & - \\
TDEM (SE) & 1.37 & - \\
Borehole Logging & 1.58 & $15 \%$ \\
\hline
\end{tabular}


Though the usual deviation from the TRT in electrical geophysical methods was established by the authors [33] to be around 14\%, in this scenario, the low resolution obtained in the layers near the surface due to the size of the loop in the TDEM method did not allow for a realistic estimation of that deviation.

The TDEM results in Table 7 are divided in two sections because there was horizontal variation in the first $200 \mathrm{~m}$ of the 2D profile, as shown in Figure 7.

The effects of the variations in the water table could affect the thermal conductivity value in this kind of geological environment (sedimentary layers) thorough the year. In this case, the borehole logging was performed in summer, so the thermal conductivity in other seasons could be higher due to the ascension of said water table.

\section{Conclusions}

Through the carried out geophysical works, the geothermal gradient was determined up to a depth of $685 \mathrm{~m}$ (the depth of the drilling). The depth of the bedrock and its inclination in the area were also established. Likewise, the most superficial geology data (up to $200 \mathrm{~m}$ ) were used to establish the conditions of the thermal conductivity of the ground for low-enthalpy geothermal systems in the location.

Temperatures from the borehole logging were not as high as expected, although two promising turning points in the geothermal gradient were found, as can be seen in Figure 10. These turning points seemed to be in line with the water inlets from two sandy layers at around -550 and $-650 \mathrm{~m}$ of depth.

The position of the bedrock was established (Figure 7) and may be useful in further research in the area. The hypothesis here is that if the borehole was drilled in the NW part of the profile, where the bedrock is not as deep (Figure 7), the temperatures would have been higher. Temperature logging in many different boreholes along the south half of the Duero basin is currently being carried out by our research group, and the results and conclusions will be sources of future publications. The use of TEM apparent resistivity curves for a more precise interpretation of the deep TDEM soundings will also be considered for a future research.

The thermal conductivity of the ground for shallow geothermal systems was also estimated from the data of the borehole logging and the performed TDEM. This was carried out by following methods presented in previous works [33]. By nature, the TDEM method offers much less definition in the most superficial layers, so the expected deviation from a TRT that would have been performed in the area is not included here. However, the expected deviation from a TRT for the more reliable data in shallow layers from the borehole logging is included, again following the work cited above.

Author Contributions: Conceptualization, I.M.N., C.S.B. and P.C.G.; methodology, I.M.N., P.C.G. and A.F.M.; validation, I.M.N., P.C.G. and C.S.B.; formal analysis, I.M.N., P.C.G. and C.S.B.; investigation, I.M.N. and P.C.G.; resources, P.C.G., A.F.M. and D.G.-A.; software, I.M.N., P.C.G. and J.C.G.; data curation, J.C.G.; writing-original draft preparation, I.M.N.; writing-review and editing, P.C.G., C.S.B., A.F.M. and D.G.-A.; visualization, I.M.N., P.C.G., C.S.B., A.F.M. and D.G.-A.; supervision, P.C.G., A.F.M. and D.G.-A.; project administration, A.F.M. and D.G.A. All authors have read and agreed to the published version of the manuscript.

Funding: This research received no external funding.

Acknowledgments: The authors would like to thank the Department of Cartographic and Land Engineering of the Higher Polytechnic School of Avila, University of Salamanca, for allowing us to use their facilities and their collaboration during the experimental phase of this research. The authors also want to thank the University of Salamanca and Santander Bank for providing a pre-doctoral grant (Training of University Teachers Grant) to the corresponding author of this paper; this grant made the realization of the present work possible.

Conflicts of Interest: The authors declare no conflict of interest.

\section{Appendix A}

Here, the chemical composition and $\mathrm{pH}$ of the thermal water from Figure 6 and Table 4 are included when available. 
Table A1. Chemical composition of the thermal water from locations in Figure 6 and Table 4 [25].

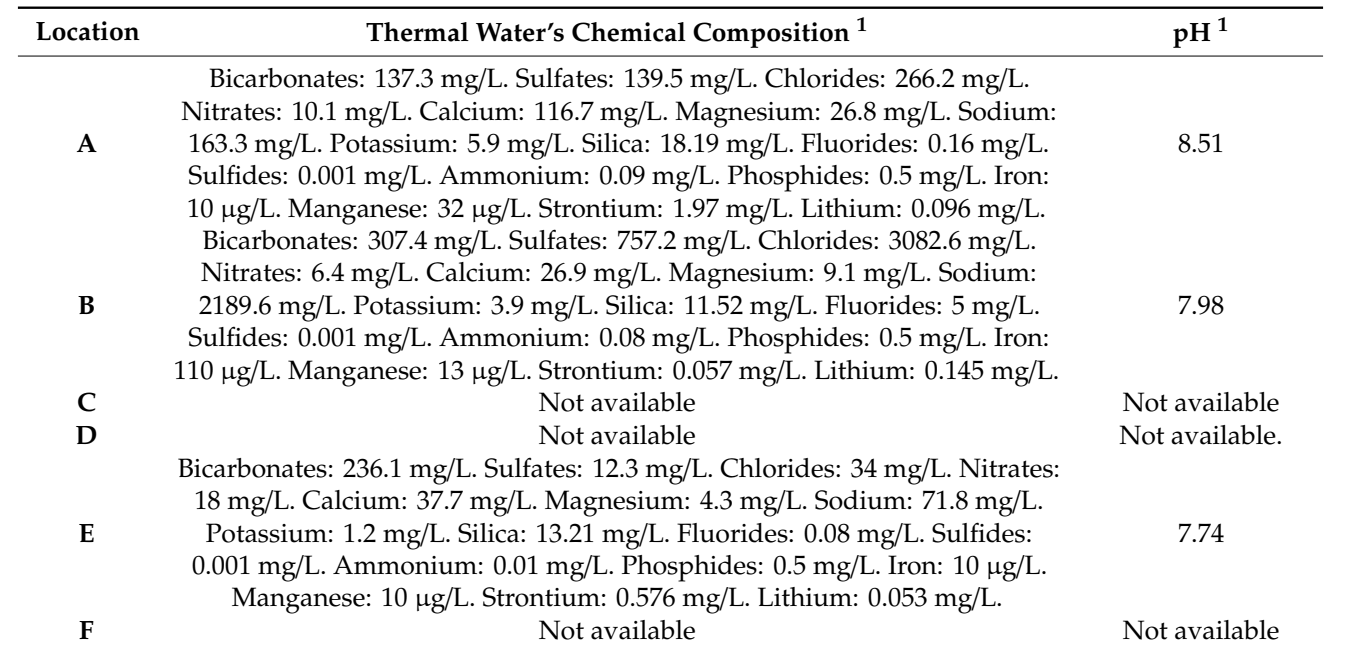

1 Source: Instituto Geológico y Minero de España. Inventario de aguas termales de España. Location A Ref. 2/293. Location B Ref. 2/292. Location E Ref. 3/23.

\section{Appendix B}

The complete borehole logging, from the surface to $-531 \mathrm{~m}$ of depth, is included here.

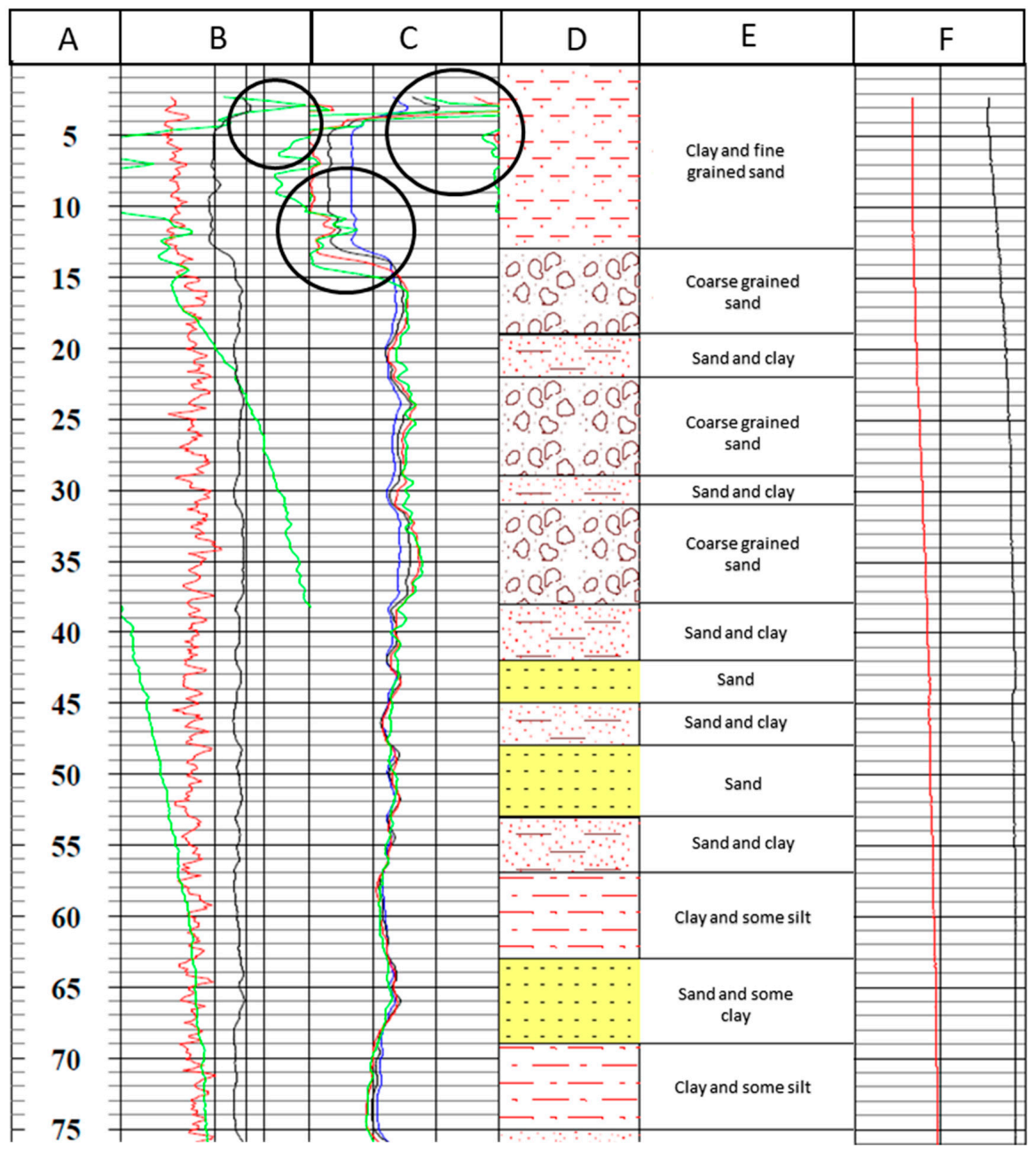

Figure A1. Borehole logging report (from 0 to $-75 \mathrm{~m}$ ). 
The black circles in Figure A1 show abnormalities at the beginning of the borehole logging due to the characteristics of the soil or the outlet of the sounding. The SP also presented some abnormal behavior until around $-75 \mathrm{~m}$ of depth.

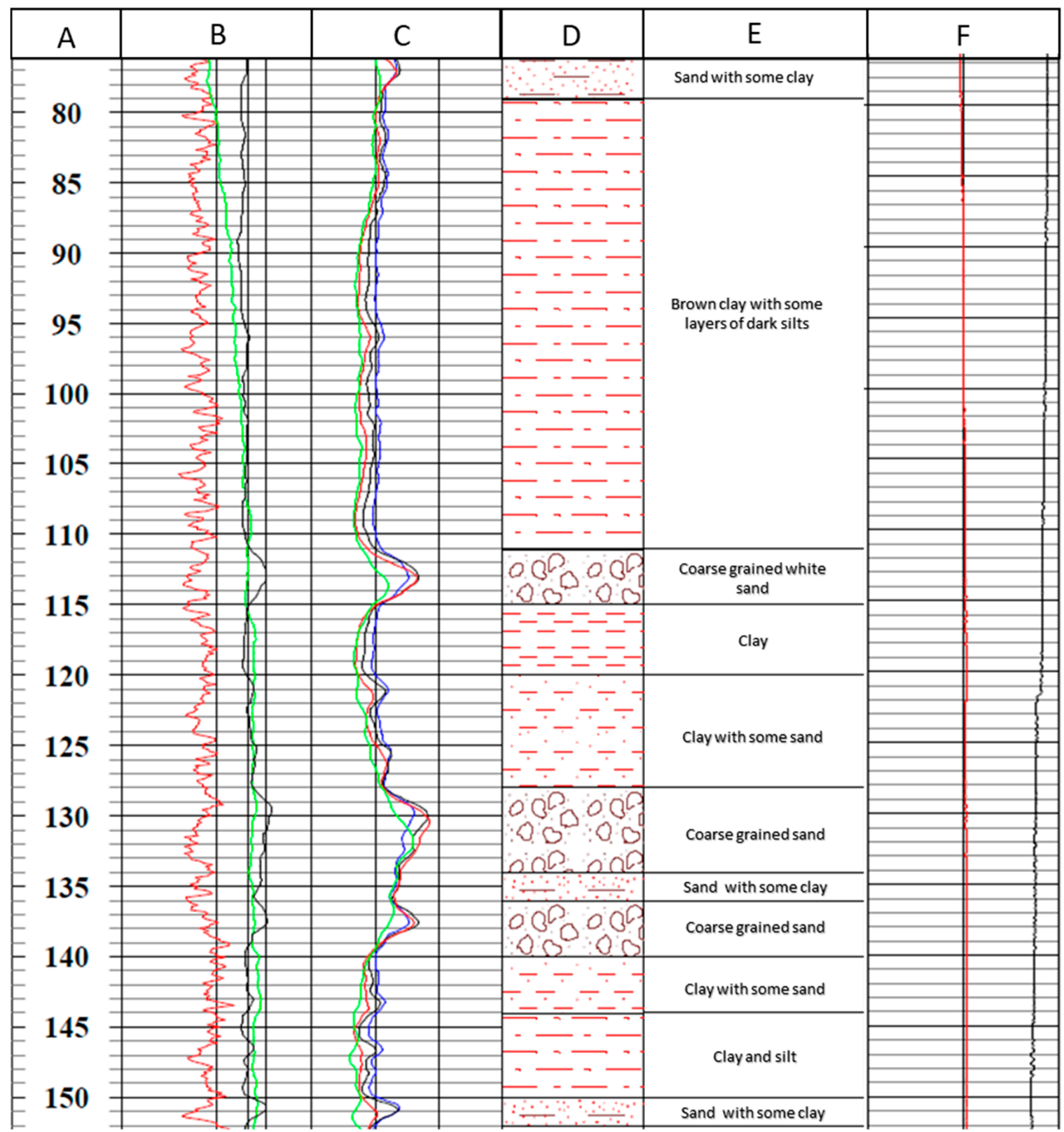

Figure A2. Borehole logging report (from -76 to $-152 \mathrm{~m}$ ). 


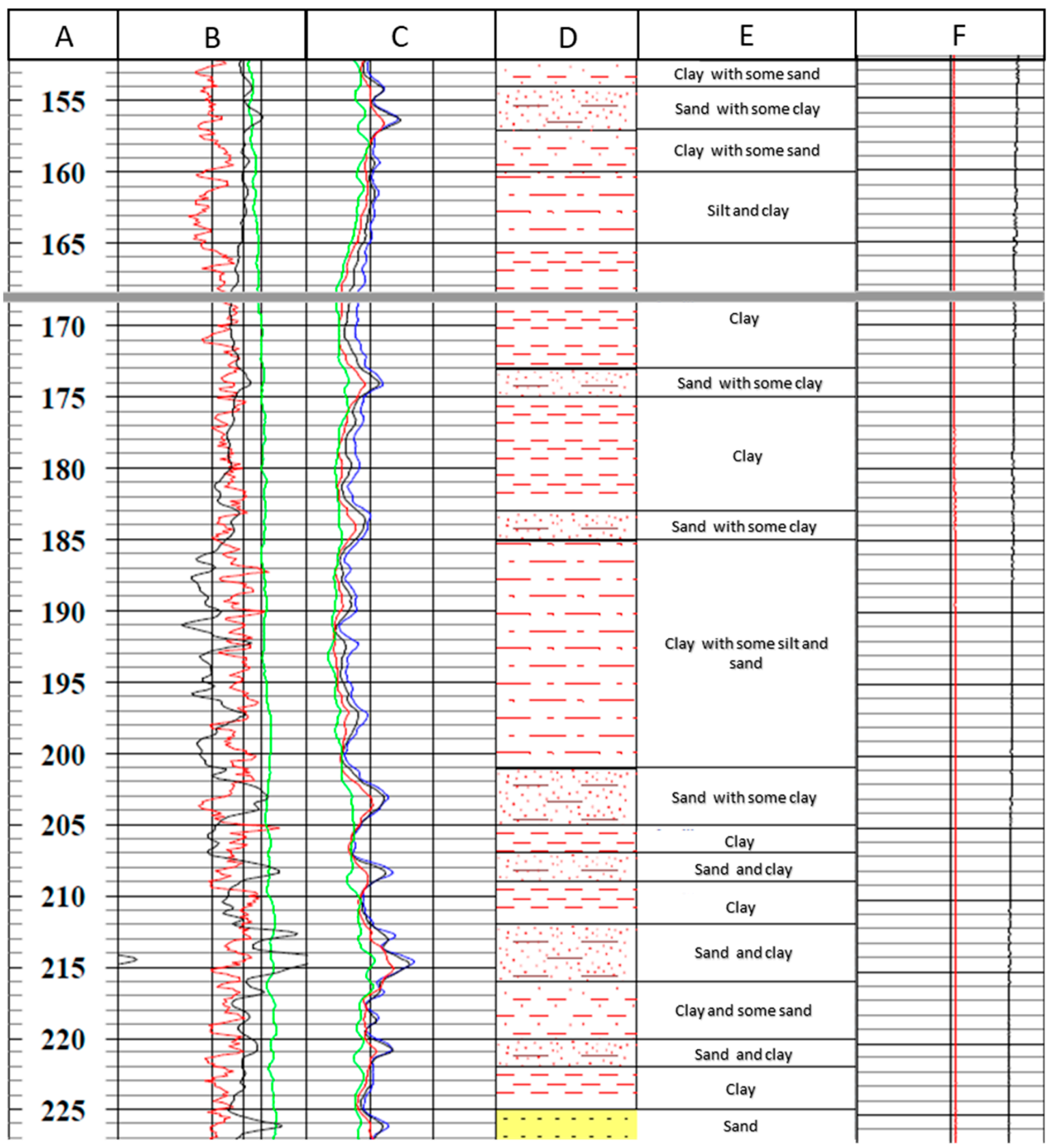

Figure A3. Borehole logging report (from -153 to $-227 \mathrm{~m}$ ). 


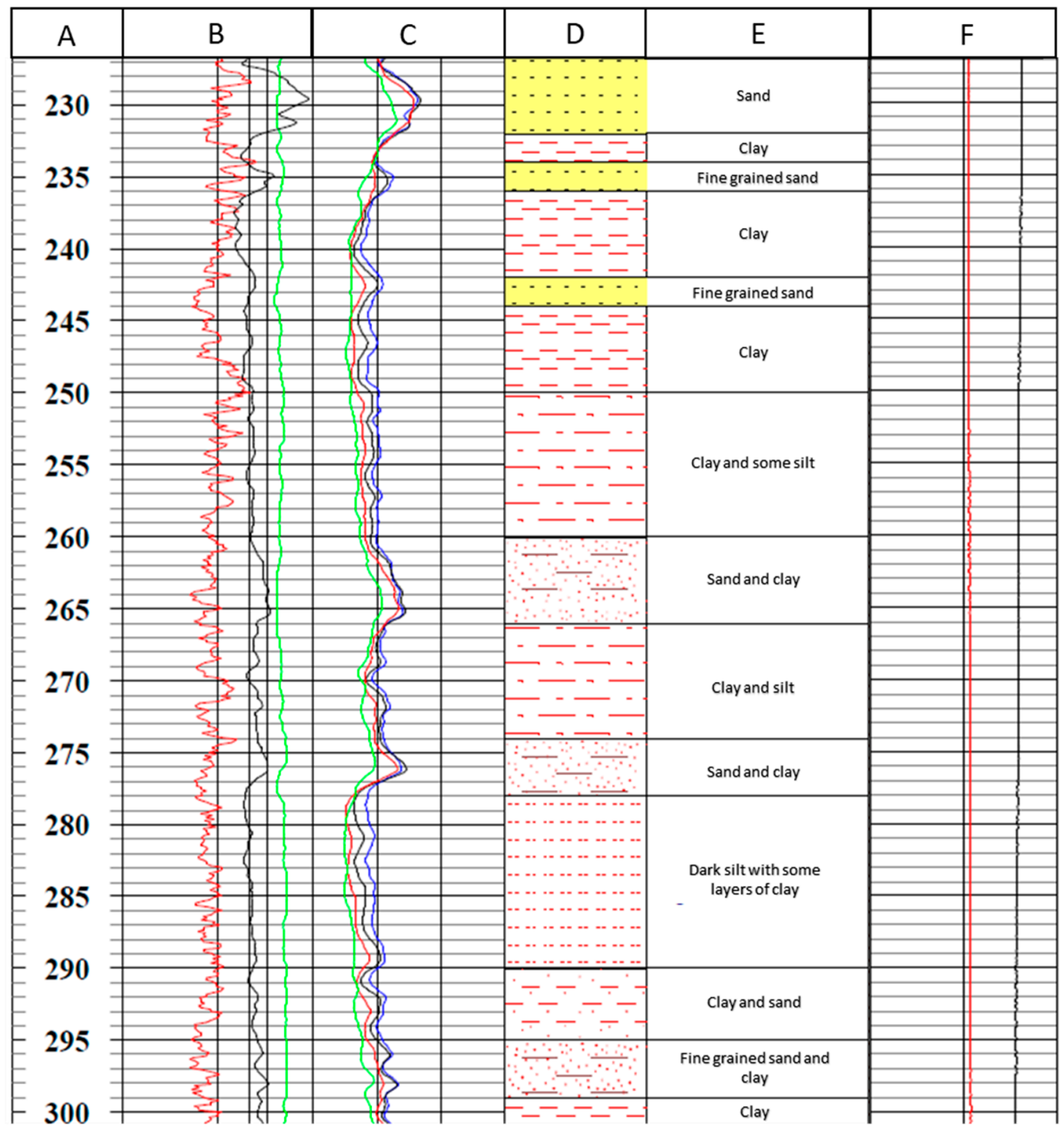

Figure A4. Borehole logging report (from -228 to $-301 \mathrm{~m}$ ). 


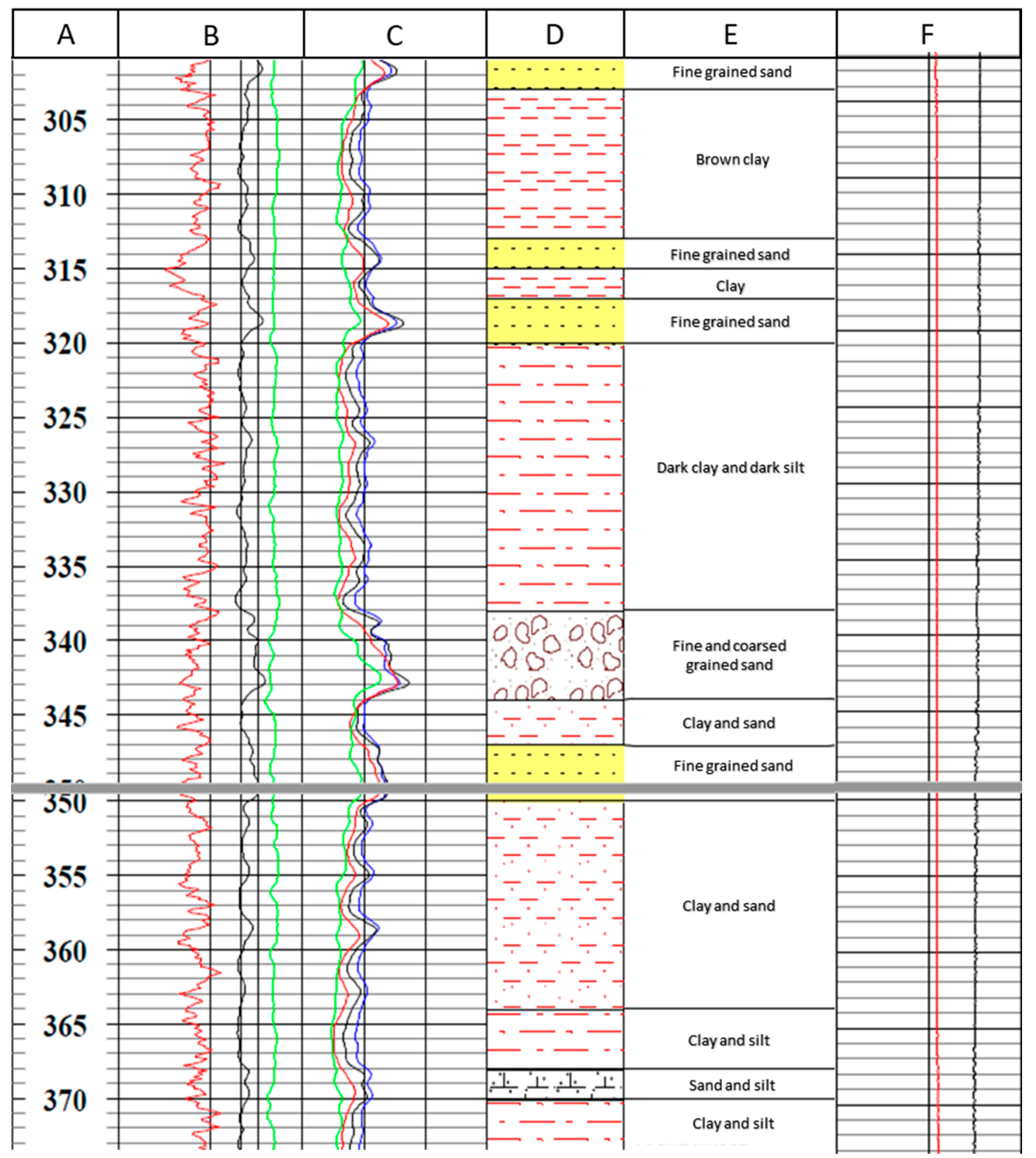

Figure A5. Borehole logging report (from -302 to $-373 \mathrm{~m}$ ). 


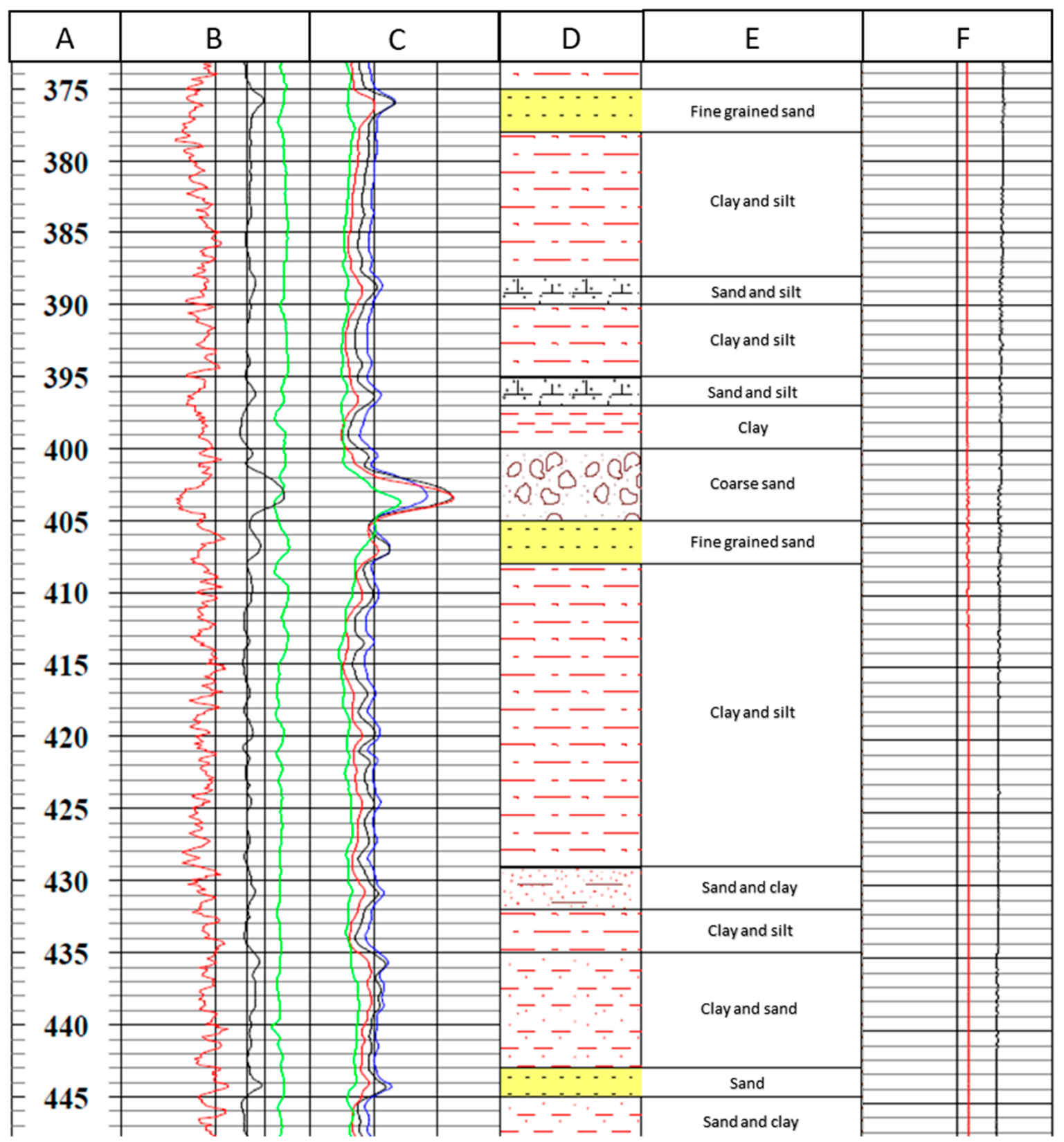

Figure A6. Borehole logging report (from -374 to $-447 \mathrm{~m}$ ). 


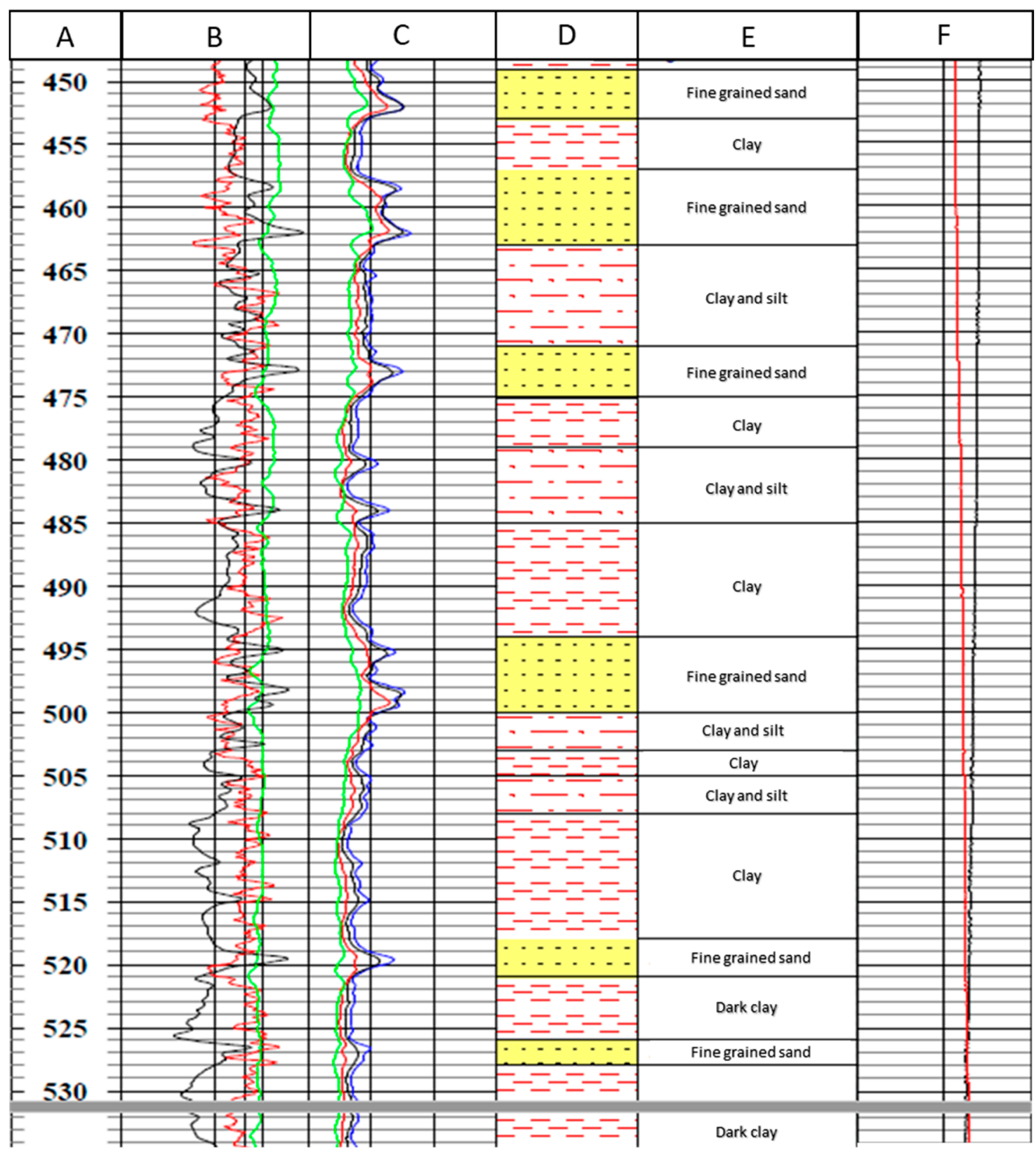

Figure A7. Borehole logging report (from -448 to $-534 \mathrm{~m}$ ).

\section{References}

1. Stefaniuk, M.; Maćkowski, T.; Sowiżdżał, A. Geophysical Methods in the Recognition of Geothermal Resources in Poland-Selected Examples. In Renewable Energy Sources: Engineering, Technology, Innovation; Springer: Cham, Swizerland, 2018; pp. 561-570.

2. Pussak, M.; Bauer, K.; Stiller, M.; Bujakowski, W. Improved 3D seismic attribute mapping by CRS stacking instead of NMO stacking: Application to a geothermal reservoir in the Polish Basin. J. Appl. Geophys. 2014, 103, 186-198. [CrossRef]

3. Isherwood, W.F.; Mabey, D.R. Evaluation of Baltazor known geothermal resources area, Nevada. Geothermics 1978, 7, 221-229. [CrossRef]

4. De Giorgi, L.; Leucci, G. Study of shallow low-enthalpy geothermal resources using integrated geophysical methods. Acta Geophys. 2015, 63, 125-153. [CrossRef] 
5. Pálmason, G. Geophysical methods in geothermal exploration. In Proceedings of the 2nd UN Symposium on the Development and Use of Geothermal Resources, San Francisco, CA, USA, 20-29 May 1975; Volume 2, pp. $1175-1184$.

6. Wu, G.; Hu, X.; Huo, G.; Zhou, X. Geophysical exploration for geothermal resources: An application of MT and CSAMT in Jiangxia, Wuhan, China. J. Earth Sci. 2012, 23, 757-767. [CrossRef]

7. Montoya, F.G.; Aguilera, M.J.; Manzano-Agugliaro, F. Renewable energy production in Spain: A review. Renew. Sustain. Energy Rev. 2014, 33, 509-531. [CrossRef]

8. Banda, E.; Albert-Beltran, J.; Torné, M.; Fernàndez, M. Regional geothermal gradients and lithospheric structure in Spain. In Terrestrial Heat Flow and the Lithosphere Structure; Springer: Berlin/Heidelberg, Germany, 1991; pp. 176-186.

9. Piña-Varas, P.; Ledo, J.; Queralt, P.; Marcuello, A.; Bellmunt, F.; Hidalgo, R.; Messeiller, M. 3-D magnetotelluric exploration of Tenerife geothermal system (Canary Islands, Spain). Surv. Geophys. 2014, 35, 1045-1064. [CrossRef]

10. Navarro, J.Á.S.; López, P.C.; Perez-Garcia, A. Evaluation of geothermal flow at the springs in Aragon (Spain), and its relation to geologic structure. Hydrogeol. J. 2004, 12, 601-609. [CrossRef]

11. EU. DIRECTIVE (EU) 2018/2001 OF THE EUROPEAN PARLIAMENT AND OF THE COUNCIL of 11 December 2018 on the Promotion of the Use of Energy from Renewable Sources. Off. J. Eur. Union 2018, 5, 82-209.

12. Sáez Blázquez, C.; Farfán Martín, A.; Nieto, I.M.; González-Aguilera, D. Economic and environmental analysis of different district heating systems aided by geothermal energy. Energies 2018, 11, 1265. [CrossRef]

13. Harvey, C.C.; Harvey, M.C. The prospectivity of hotspot volcanic islands for geothermal exploration. In Proceedings of the World Geothermal Congress 2010, Bali, Indonesia, 25-30 April 2010.

14. Colmenar-Santos, A.; Folch-Calvo, M.; Rosales-Asensio, E.; Borge-Diez, D. The geothermal potential in Spain. Renew. Sustain. Energy Rev. 2016, 56, 865-886. [CrossRef]

15. Chamorro, C.R.; García-Cuesta, J.L.; Mondéjar, M.E.; Linares, M.M. An estimation of the enhanced geothermal systems potential for the Iberian Peninsula. Renew. Energy 2014, 66, 1-14. [CrossRef]

16. Schellschmidt, R.; Hurter, S.; Förster, A.; Huenges, E. Atlas of Geothermal Resources in Europe; Office for Official Publications of the European Communities: Brussels, Belgium, 2002.

17. Mapa Hidrogeológico de España a escala 1:100.000. (Hojas 36, 37 y 38); IGME, Instituto Geológico y Minero de España: Madrid, Spain. Available online: https:/info.igme.es/cartografiadigital/geologica/mapa.aspx? parent $=$. ./tematica/tematicossingulares.aspx\&Id=19 (accessed on 1 July 2020).

18. Harthill, N. Time-domain electromagnetic sounding. IEEE Trans. Geosci. Electron. 1976, 14, $256-260$. [CrossRef]

19. Rodriguez, J.C.; JC, R. Inversion of TDEM (near-zone) sounding curves with catalog interpolation. Pascal Francis 1978, 73, 57-69.

20. Nabighian, M.N.; Macnae, J.C. Time domain electromagnetic prospecting methods. Electromagn. Methods Appl. Geophys. 1991, 2 Part A, 427-509.

21. Munkholm, M.S.; Sørensen, K.I.; Jacobsen, B.H. Characterization and in-field suppression of noise in hydrogeophysics. In Symposium on the Application of Geophysics to Engineering and Environmental Problems; Society of Exploration Geophysicists: Tulsa, OK, USA, 1995; pp. 339-347.

22. Nieto, I.M.; Martín, A.F.; Blázquez, C.S.; Aguilera, D.G.; García, P.C.; Vasco, E.F.; García, J.C. Use of 3D electrical resistivity tomography to improve the design of low enthalpy geothermal systems. Geothermics 2019, 79, 1-13. [CrossRef]

23. Law, D.; Noh, K.A.M.; Rafek, A.G.M. Application of Transient Electromagnetic (TEM) Method for Delineation of Mineralized Fracture Zones. In IOP Conference Series: Earth and Environmental Science; IOP Publishing: Bristol, UK, 2019; Volume 279, p. 012038.

24. Mount Sopris Instruments, Denver, CO, USA. Available online: https://mountsopris.com/ (accessed on 1 July 2020).

25. Baeza Rodríguez-Caro, J.; López Geta, J.A.; Ramírez Ortega, A. Aguas Minerales y Termales de España; IGME, Instituto Geológico y Minero de España: Madrid, Spain; Chapter 6.1, ISBN: 84-7840-424-4. Available online: https://aguasmineralesytermales.igme.es/inventario-aguas-minerales-termales (accessed on 1 July 2020).

26. MAGNA 50, MAPA GEOLÓGICO DE ESPAÑA 1:50.000, HOJA 481, Nava de Arévalo; IGME, Instituto Geológico y Minero de España: Madrid, Spain, 2003. 
27. Carreras, F.; Molina, E. Memoria de la Hoja No 481 (Nava de Arévalo). In Mapa geológico de España E 1:50.000 (MAGNA); Segunda Serie, Primera Edición; IGME: Madrid, Spain, 1982; Depósito Legal M-29894-1982; ISSN 0373-2096.

28. Aguas Minerales y Termales de España; IGME, Instituto Geológico y Minero de España: Madrid, Spain; Mapa Hidrogeológico de España a escala 1:100.000. (Hoja 37). Available online: https://info.igme.es/ cartografiadigital/geologica/mapa.aspx?parent=../tematica/tematicossingulares.aspx\&Id=19 (accessed on 1 July 2020).

29. Ministerio de Industria. Energía y Turismo, IDAE (Instituto Para la Diversificación y Ahorro de la Energía), Manual de Geotermia; Ministerio de Industria: Madrid, Spain, 2008.

30. Sáez Blázquez, C.; Carrasco García, P.; Nieto, I.M.; Maté-González, M.Á.; Martín, A.F.; González-Aguilera, D. Characterizing Geological Heterogeneities for Geothermal Purposes through Combined Geophysical Prospecting Methods. Remote Sens. 2020, 12, 1948. [CrossRef]

31. Blázquez, C.S.; Martín, A.F.; García, P.C.; González-Aguilera, D. Thermal conductivity characterization of three geological formations by the implementation of geophysical methods. Geothermics 2018, 72, 101-111. [CrossRef]

32. Sanner, B.; Hellström, G.; Spitler, J.; Gehlin, S. Thermal response test-current status and world-wide application. In Proceedings of the World Geothermal Congress, Antalya, Turkey, 24-29 April 2005; International Geothermal Association: Bochum, Germany, 2005; Volume 1436, p. 2005.

33. Sáez Blázquez, C.; Martín Nieto, I.; Farfán Martín, A.; González-Aguilera, D.; Carrasco García, P. Comparative Analysis of Different Methodologies Used to Estimate the Ground Thermal Conductivity in Low Enthalpy Geothermal Systems. Energies 2019, 12, 1672. [CrossRef]

Publisher's Note: MDPI stays neutral with regard to jurisdictional claims in published maps and institutional affiliations. 